\title{
Tone - Melody Matching in Chaozhou Songs: A Corpus Analysis
}

\author{
Xi Zhang \& Ian Cross
}

Centre for Music and Science, Faculty of Music, University of Cambridge

\section{Introduction}

- Chaozhou dialect is a branch of Southern Min Chinese with eight tones and a wealth of tone sandhi, providing a complex context which can be expected to shape Chaozhou songs.

- This paper focuses on exploring the degree to which lexical tone and musical melody were matched in terms of pitch direction in different genres of Chaozhou songs by means of analysis of a corpus of notated songs.

\begin{tabular}{|c|c|c|c|c|c|}
\hline Approach & ID & $\begin{array}{l}\text { Groups of } \\
\text { tones }\end{array}$ & Citation tones & $\begin{array}{l}\text { Tones in the context } \\
\text { with sandhi }\end{array}$ & $\begin{array}{l}\text { Relation between two } \\
\text { tones (example) }\end{array}$ \\
\hline \multirow{3}{*}{$\begin{array}{l}\text { Emphasis on } \\
\text { ending pitch } \\
\text { of tones }\end{array}$} & 1 & High-pitch & $55, \underline{54}, 35$ & $55, \underline{54}, 35,24$ & \multirow{3}{*}{$\begin{array}{l}\text { E.g. the relation betweer } \\
\text { ' } 55 \text { ' and ' } 53 \text { ' is the } \\
\text { transition from High- to } \\
\text { Mid-pitch group (H-M). }\end{array}$} \\
\hline & 2 & Mid-pitch & $53,33,213$ & $53,33,23,213$ & \\
\hline & 3 & Low-pitch & $11, \underline{21}$ & $42,11,21 / \underline{21}, 12$ & \\
\hline \multirow{3}{*}{$\begin{array}{l}\text { Emphasis on } \\
\text { tone-pitch } \\
\text { extreme }\end{array}$} & 1 & High-pitch & $55, \underline{54}, 35,53$ & $55,54,35,53$ & \multirow{3}{*}{$\begin{array}{l}\text { E.g. the relation betweer } \\
\text { ' } 55 \text { ' and ' } 53 \text { ' is the } \\
\text { transition from High- to } \\
\text { High-pitch group }(\mathrm{H}-\mathrm{H})\end{array}$} \\
\hline & 2 & Mid-pitch & 33 & $33,23,24,42$ & \\
\hline & 3 & Low-pitch & $11,213, \underline{21}$ & $11,213,12,21 / \underline{21}$ & \\
\hline
\end{tabular}

Table 1. Chaozhou citation tones and sandhi tones. Different categorisations of tones based on emphasis on different aspects of tones were examined.

\section{Results and discussion}

- A high degree of tone-melody matching was found, with $89 \%$ in folk songs and $78 \%$ in contemporary songs (see Table 4 for the values in bold). The result suggests that folk singers are more likely to follow the rule of tone-melody matching than are contemporary composers. Chaozhou tone sandhi has an effect on the tone-melody matching in Chaozhou songs (see different Pearson's $r$ values between Table 2 and Table 3).

- The Chaozhou tones that are realised in context can be categorised into high-, mid- and low-pitch groups, by emphasising the tone-pitch extremes, rather than the ending pitch of tones that was found to be operational in an influential perceptual study of Cantonese song (Wong \& Diehl, 2002; see Table 4 for the comparison between two different analytical approaches).

- In analyses of sequences where single tones are each performed on a pair of melodic notes, the relationship between the first notes of each successive note-pair has the most consistent influence on tonemelody matching (see Table 4 for the comparison between different modes).

- The results confirm that the association between sequences of tones and their corresponding melodic intervals. It hints that the interval size reflected the pitch distance between two tones in different registers (e.g. Low-, Mid-, High-pitch) might introduce a categorical boundary in production or perception.

\section{Bibliography}

Wong, Patrick C M, \& Diehl, R. L. (2002). How Can the Lyrics of a Song in a Tone Language Be Understood? Psychology of Music (Vol. 30).

Ladd, D. R., \& Kirby, J. P. (2020). Tone-melody Matching in Tone Language Singing. In C Gussenhoven \& A. Chen (Eds.), Oxford Handbook of Linguistic Prosody (pp. 676-687).

\begin{tabular}{|c|c|c|c|c|}
\hline & \multicolumn{3}{|c|}{ Emphasis on the tone-pitch extreme } \\
\hline & & I-I & E-E & E-I \\
\hline \multirow{4}{*}{$\begin{array}{l}\text { Folk } \\
\text { songs }\end{array}$} & Similar & $1271(89 \%)$ & $1134(79 \%)$ & $1227(86 \%)$ \\
\hline & Oblique-I & $85(6 \%)$ & $188(13 \%)$ & $122(9 \%)$ \\
\hline & Oblique-II & $62(4 \%)$ & $75(5 \%)$ & $61(4 \%)$ \\
\hline & Contrary & $14(1 \%)$ & $35(2 \%)$ & $22(2 \%)$ \\
\hline \multirow{4}{*}{$\begin{array}{l}\text { Contemporary } \\
\text { songs }\end{array}$} & Similar & $637(78 \%)$ & $552(68 \%)$ & $623(76 \%)$ \\
\hline & Oblique-I & $121(15 \%)$ & $158(19 \%)$ & $124(15 \%)$ \\
\hline & Oblique-II & $29(4 \%)$ & $49(6 \%)$ & $27(3 \%)$ \\
\hline & Contrary & $28(3 \%)$ & $56(7 \%)$ & $41(5 \%)$ \\
\hline
\end{tabular}

\section{Method}

- Materials. 10 folk songs and 10 contemporary songs were included in the corpus.

- Procedure. We calculated the rate of matches and mismatches between two consecutive tones and two consecutive notes, taking the form of similar motion, oblique motion or contrary motion (Ladd \& Kirby, 2020). The relationship between two tones can be expressed by $\Delta \mathrm{T}=\mathrm{t} 1-\mathrm{t} 2$, where $\mathrm{t} 1$ and $\mathrm{t} 2$ are the group IDs of the two consecutive tones (Table 1). The pitch directions of two successive notes are identified by $\Delta \mathrm{P}=\operatorname{sign}(\mathrm{p} 2-\mathrm{p} 1)$, where $\mathrm{p} 1$ and $\mathrm{p} 2$ are the pitch levels of the musical notes. The degree of tone-melody correspondence is then measured by the number of matches (similar motions). The mismatches, on the other hand, are divided into oblique-I motions, oblique-II motions and contrary motions (Figure 1).
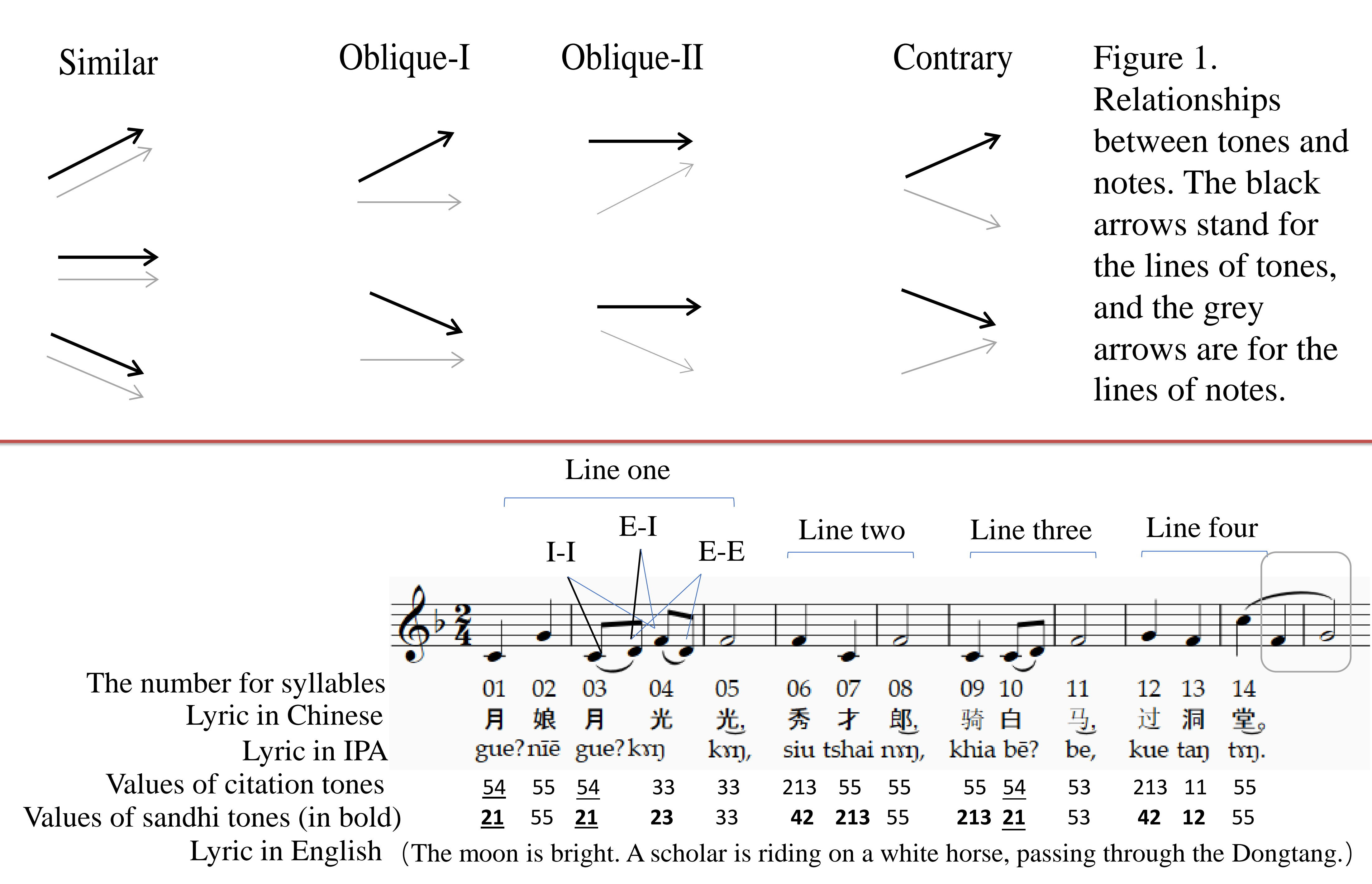

Figure 2. Examples from the folk song 'Moon lady. Different modes of note-transition were labelled as 'I-I' (sequential note-initial relationship, see note C-F), 'E-I' (note-ending-note-initial relationship, see note D-F) and 'E-E' (sequential note-ending relationship, see note D-D). The notes $F$ and $G$ (in the grey frame) at the end of line four were excluded because they serve as decoration to the melody. Transition from a phrase to another, e.g., syllable 05 to 06,08 to 09,11 to 12 and their corresponding notes were excluded too.

\begin{tabular}{|l|l|l|l|l|}
\hline Genre of songs & Categorisation of tones & I-I & E-E & E-I \\
\hline Folk $(n=1432)$ & Emphasis on the tone-pitch extreme & 0.87 & 0.77 & 0.84 \\
& Emphasis on the ending pitch of tones & 0.62 & 0.58 & 0.60 \\
\hline Contemporary $(n=815)$ & Emphasis on the tone-pitch extreme & 0.79 & 0.65 & 0.73 \\
& Emphasis on the ending pitch of tones & 0.56 & 0.51 & 0.53
\end{tabular}

Table 2. The outcomes of Pearson's $r$ correlation coefficient test between categorisations of tones and modes of note-transition, based on the data of tones in the context with sandhi.

\begin{tabular}{|l|l|l|l|l|}
\hline Genre of songs & Categorisation of tones & I-I & E-E & E-I \\
\hline Folk $(n=1432)$ & Emphasis on the tone-pitch extreme & 0.22 & 0.22 & 0.22 \\
\hline Contemporary $(n=815)$ & Emphasis on the ending pitch of tones & 0.17 & 0.18 & 0.16 \\
\hline & Emphasis on the tone-pitch extreme & 0.18 & 0.20 & 0.18 \\
\hline
\end{tabular}

Table 3. The outcomes of Pearson's $r$ correlation coefficient test between categorisations of tones and modes of note-transition, based on the data of citation tones.

Emphasis on ending pitch of tones

\begin{tabular}{|c|c|c|c|} 
I-I & E-E & E-I
\end{tabular}

$860(60 \%) \quad 833(58 \%) \quad 848(59 \%)$

$290(20 \%) \quad 329(23 \%) \quad 309(22 \%)$

$216(15 \%) \quad 165(12 \%) \quad 197(14 \%)$

$66(5 \%) \quad 105(7 \%) \quad 78(5 \%)$

$460(56 \%) \quad 439(54 \%) \quad 447(55 \%)$

$236(29 \%) \quad 249(31 \%) \quad 243(30 \%)$

$66(8 \%) \quad 62(8 \%) \quad 68(8 \%)$

\begin{tabular}{l|l|l}
$53(7 \%)$ & $65(8 \%)$ & $57(7 \%)$
\end{tabular} 